\title{
NUMERICAL MODELING OF MICROSCALE AND MESOSCALE BED FORMS UNDER UNSTEADY DISCHARGE
}

\author{
Yasuyuki SHIMIZU \\ Member of JSCE, Dr. of Eng., Professor, Hydraulic Research Laboratory, Hokkaido University (Kita-13, Nishi-8 \\ Kita-ku, Sapporo 060-8628, Japan)
}

\begin{abstract}
Brief description of two different morphodynamic numerical models has been presented within the scope of this lecture. One of the proposed models is vertical two-dimensional and is capable of simulating dynamic features of microscale bed forms, particularly river dunes. Another one is a depth-averaged morphologic model that can simulate evolution of mesoscale bed forms, particularly sand bars. These numerical models can simulate bedform morphodynamics for both steady and temporally varying flows. In this work, attention has been given to the evolution of river dunes and sand bar under temporally varying flows.
\end{abstract}

Key Words: River morphodynamics, numerical simulation, river dunes, sand bars

\section{INTRODUCTION}

Morphodynamic behavior of micro and mesoscale river-bed features such as ripples, dunes, sand bars etc is significant in evaluation of flow resistance and other characteristics associated with river environments; however these aspects of river engineering practice have been given relatively little attention and there is no existing tool for making physically based prediction of geometric characteristics of such bed forms as well as total flow resistance induced by them for arbitrary steady or unsteady flow condition.

Brief description of two different morphodynamic numerical models has been presented within the scope of this lecture. These models are capable of simulating vertical and horizontal two-dimensional features of microscale and mesoscale bed forms respectively for steady or temporally varying flows. In this work, attention has been given to the evolution of river dunes and sand bar under temporally varying flows.

\section{SIMULATING MESOSCALE BED FORMS}

Consideration of sand bar evolution under unsteady discharge, for instance during flood event, is important in river engineering practice. Moreover, behavior of downstream morphology induced by several control structures is also subjected to the consideration of unsteady flow.

Proposed model ${ }^{1)}$ solves depth-averaged flow equations with a simplest zero-equation turbulence closure in a generalized coordinate system. A two-dimensional sediment continuity equation for bedload transport has been used considering the effect of secondary current near the bed. Computation has been performed for variety of boundary conditions in upstream and downstream end to evaluate their effect on ultimate results. Results of numerical computation have been verified against laboratory observations (Fig.1, top plot). The model successfully replicates the evolution process of sand bars during rising and falling stages of flows. The model is able to reproduce hysteresis characteristics during evolution of sand bars for strongly temporally varying flows; this is in good agreement with observation.

\section{SIMULATING MICROSCALE BED FORMS}

A coupled morphodynamic model ${ }^{2)}$, which is two-dimensional in the streamwise and vertical directions, has been developed to compute evolution 

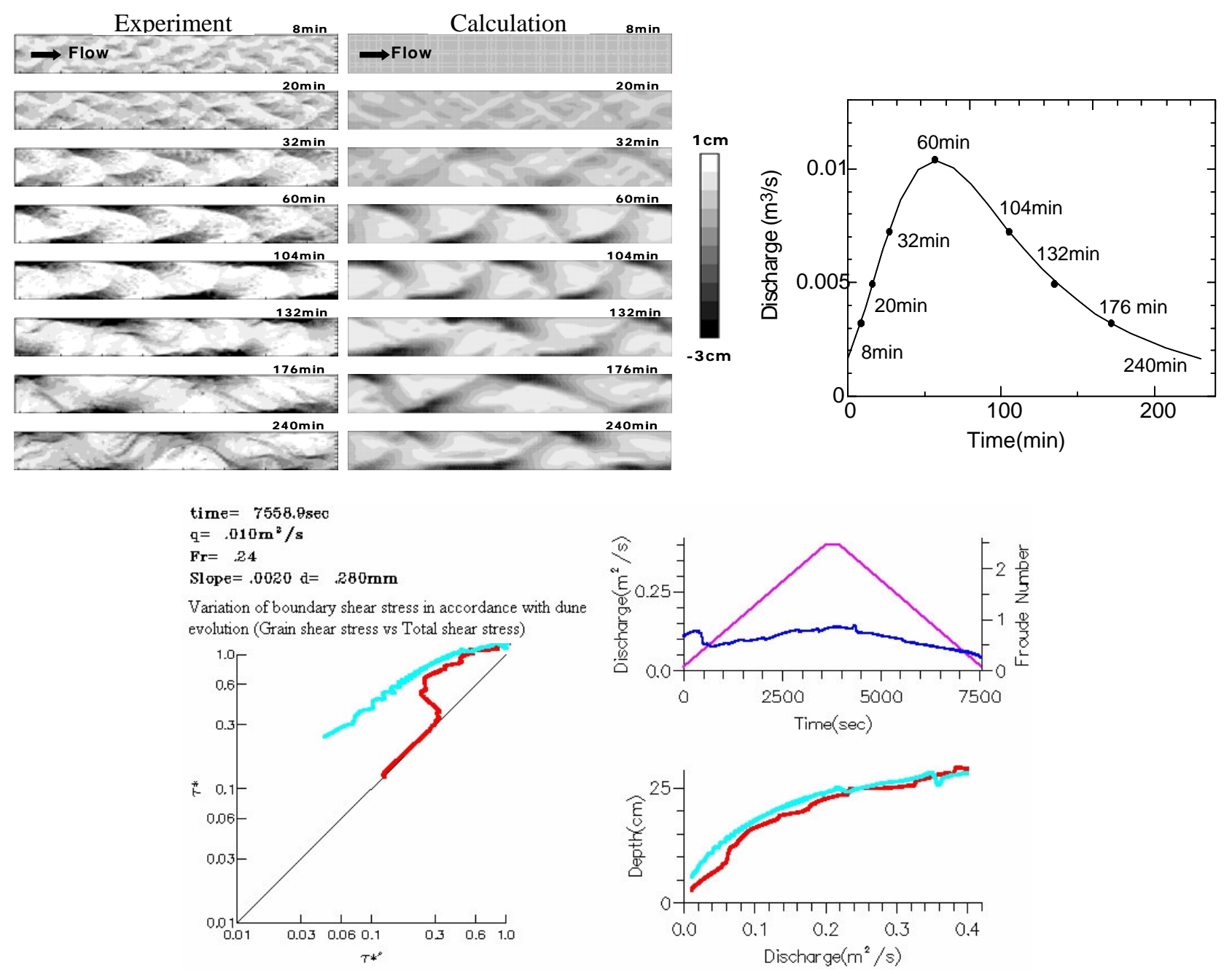

Fig.1 Sand bar formation under unsteady discharge (top figure) and evolution of dune-induced physical characteristics in varying flows (bottom figure)

of microscale bed forms. The model explicitly treats unsteadiness and nonhydrostatic effects. In addition, an enhanced k-e turbulence closure with nonlinear terms is incorporated in the present model in order to allow better predictions of Reynolds stress anisotropy in regions with flow separation. Non-equilibrium bedload sediment transport is treated using an Eulerian stochastic formulation of the sediment exchange process in terms of pick up and deposition functions proposed by Nakagawa and Tsujimosto (1980). The model reproduces the temporal evolution of microscale bed form characteristics, particularly dunes, for steady or temporally varying flows and is able to accurately replicate the physical properties associated with bed form evolution under such flows (Fig.1, bottom plot). Based on comparison to measurements, the model results also appear to provide accurate predictions of the pressure or form drag over bed forms for both simple steady flows and temporally varying flows. This numerical model is able to replicate bed shear stress variation in accordance with the variation of form drag produced by the temporal growth or decay of bed forms.

\section{CONCLUSION}

A couple of state-of-the-art numerical models have been developed that can be used to simulate microscale and mesoscale bed form evolution in physically based manner. Such kind of problems has been treated in the past only using empirical methods. The proposed numerical models appear to be applicable for solving practical problem associated with bed form evolution processes under steady or varying flows.

\section{REFERENCES}

1) Kobayashi, K., Shimizu, Y., Giri, S. and Watanabe, Y.: Morphodynamic modeling of sand bar evolution under unsteady flow, Proc. Int. Conf. Fluv. Hydraul., River Flow, pp.1221-1229, 2006.

2) Giri, S. and Shimizu, Y.: Numerical computation of sand dune migration with free surface flow, Water Resour. Res., Vol.42, W10422, doi:10.1029/2005WR004588, 2006.

(Received September 30, 2006) 